\title{
Self-esteem levels of slum young women and perceptions on their health status and physical appearance
}

\section{MUGDHA DESHPANDE AND DESETTY RAMANAMMA}

See end of the paper for authors' affiliation

Correspondence to : DESETTY RAMANAMMA Department of Human Development and Family Studies, College of Home Science, Vasantrao Naik Marathwada Agricultural University, PARBHANI (M.S.) INDIA

Email: manraman_02@ rediffmail.com

\section{KEY WoRDS :}

Self-esteem, Slum young women, Physical appearance, Body build, Health
ABSTRACT: Two hundred slum young women was chosen at random from the 10 slum areas of Parbhani town of Marathwada region of Maharashtra state. Out of which 30 were from the middle SES group and the remaining 170 were from the low SES group. The age group of the slum young women ranged between $20 y$ rs and $25 y$ rs. The self-esteem scale for women developed by Kapadia and Verma was administered on them for assessing their self-esteem levels. Kuppuswamy's socioeconomic status scale for urban population revised by Patnam (1992) was used to assess the socioeconomic status of sample slum young women. The results reveal that majority (57\%) of the selected slum young women were assessed to have low self-esteem level followed by medium level of self-esteem (29\%) and high level of self-esteem (13\%) irrespective of their low and middle SES groups. Family background variables such as family size, family type, age and education of fathers and mothers were found to have significant influence on their self-esteem levels. Significantly a higher percentage of high self-esteem slum young women were found to have rated their personal appearance at very good $(92 \%)$, body build at very good $(74 \%)$, academic performance at good $(40 \%)$, health status at very good $(40 \%)$ category. However, majority of the low self-esteem level slum young women reported that they have perceived their personal appearance $(65 \%)$, body build $(68 \%)$ and health status $(45 \%)$ at fair level.

How to cite this paper : Deshpande, Mugdha and Ramanamma, Desetty (2015). Self-esteem levels of slum young women and perceptions on their health status and physical appearance. Internat. J. Med. Sci., 8(1\&2) : 28-33. 